\title{
Adjectives in Turkish Language
}

\section{Hasan M. Ferhan}

Assist, Lec, / Language Studies Dept., The Center for Regional Studies, Mosul Univ.

\section{Abstract}

Adjectives in Turkish Language come before the nouns. An adjective is known by the word which explains the meanings of nouns, its characteristics and things related to these nouns whether they are nouns of human beings or animals. It also shows us its numbers, characteristics and orders . An adjective differs from a noun by not taking suffixes for the cases of singular plural and possession.

Adjectives are divided into two parts according to their function: descriptive adjectives and question adjectives.

\section{Önsöz}

Türkçede sıfatlar vasıf ve belirtme isimleridir.Sıfatlar nesneleri vasıflandırma ve belirtme suretiyle karşılayan kelimedir. Sifatlar nesnelerin kendilerinin değil vasıflarının adlarıdır. Sıfatlar asıl isimleri başka olan nesnelerin bir vasfını belirttikleri zaman sıfat,tek vasıftan ibrat olan nesneleri karşıladıkları zaman isim derler.

Türkçede sıfatlar vasıflandırdıklarını isimlerin önüne gelir. Demeki sıfat bir isimin başına gelip, o ismi vasıflandıran kelimedir.

Türkçede sıfatlar,iyelik eki,isim hal ekleri ve çoğul eki de almaz. 
Sıfatlar renk, şekil, sayı, veya soru yoluyla tamamlayan kelimelerdir. Nesnelerin türlü türlü vasıfları, türlü türlü belirteleri vardır. Böyleyse sıfatlar bu vasıfların ve belirtilerin isimleridir. Sifatlar nesneleri vasıflandıma amacıyla karşılayankelimelerdir. Sifatlar isimlerin önünde olur. Sıfatlar isim çekim eki almaz.Sıfatlar isim çekim ekleri alırsa isim olur. Ali,ihtiyar kadını yolun karşısına geçiriyor. Şu anda cümle sıfattır. Ali, ihtiyarı yolun karşısına geçiriyor. Şu cümlede ihtiyar kelimesi hal eki almış olduğu için isimdir. simler birden fazla sıfat alabilir.Onun uzun, siyah saçları vardır. Dilekçe çizgisiz, beyaz kağıda yazılır ${ }^{(1)}$. Türkçede sıfatlar, yanlarındaki isim ve şekilde bulunursa bulunsun,sıfat olarak genellikle cekimsizdir. Hiç işletme eki almaz,bu bakımdan hiç bir şekilde isime uymazlar ${ }^{(2)}$. Sifatlar hakkında verdiğimiz genel bilgilerden sonra şimdi sıfat türlerini gözden geçirebiliriz.

\section{Sıfatların Türleri:}

\section{1- Niteleme sıfatları.}

\section{2-Belirtme sifatları.}

1- Niteleme sıfatları: Varlıkların biçimlerini, durumlarını, renklerini anlatan sözcüklere niteleme sıfat denilir ${ }^{(3)}$. Eski çorap, güzel yazıü, altın yüzük, süzme bal, doğru 


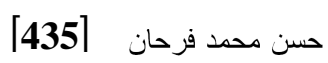

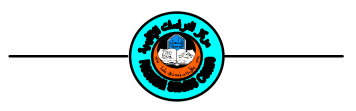

söz, geçen ay gibi sıfatların büyük kısmını bu vasıflandırma sıfatları teşkil eder. Nesnelerin ne kadar vasfi varsa o kadar da vasiflandırma sıfat vardır ${ }^{(4)}$.

2- Belirtme sıfatları: Belirtme sıfatları nesneleri belirten sifatlardır. Bu sifatlar nesnenin bünyesinde olan bir vasfı göstermez Nesneyi bir kaç bakımdan belirtmek mümkündür. Nesnenin ya yerine işaret edilir, ya sayısı gösterilir, ya nesne soru şeklinde, ya da belirsizlik belirtilir $^{(5)}$.

* şaret Sıfatları: şaret sıfatları sayılı

kelimelerdir. Bu, şu, o, bu:yakını, şu:öteyi, o:uzağı işaret eder.

şaret sıfatlarını bir ismin önünde kullanılırı ${ }^{(6)}$. Bu ev öğrencinin evidir. Şu tepede taş var. O dağlarda kar var. şaret sıfatları çoğul eki, isim hal ekleri, iyelik ekleri almazlar. Böyle, şöyle, öyle kelimeleri de işaret sıfatı görevinide yapabilir ${ }^{(7)}$.

*Sayı sıfatları: Sayı sıfatları nesneleri bakımından sayılarını bildirmek suretiyle belirten kelimelerdir ${ }^{(8)}$. Aslında sayı sıfatı beşe ayrılırlar ${ }^{(9)}$.

1- Asıl sayı sıfatları: Bunlar, önüne geldikleri isimlerin sayılarını bildirirler. Beş öğrenci, sekiz ev, yüz elli kuruş. Genellikle, asıl sayı sıfatlarında dört işlem 
yapılır. Bunlar: toplama, çıkarma, çarpmave bölmedir ${ }^{(10)}$.

Toplama: $2+5=7 \mathrm{iki}$, beş hahayedi eder

Çıkarma: 5-4=1 Beşten dört çıktı bir kaldı.

Çarpma: $4 \times 5=20$ dört kere beş, yirmi eder.

Bölme: $5 \% 4=1,25$ beş bölü dört, eşit, bir virgül yirmi beş.

2- Sira sayı sifatları: Bunlar, belirttikleri isimlerin sirasını bildiren-(i)nci-derece ekini almış olan sayılardır. Birinci, ikinci, gibi. Birinci sıra gelsin.

Sıra sayı sıfatlardan sonra gelen isimler çoğul eki alabilirler. Üçüncü sınıflar geziye gittiler. Sıra sayı sıfatlarını öğrenmek için(kaç)kelimesine -(i)nci-eki getirilir:

-kaçıcı geldi -kaçıncı oldun

-Üçüncü geldi - Birinci oldum.

3- Üleştirme sayı sıfatları: Varlıkların paylaşma ve bölünme miktarlarını bildirir.Üleştirme sıfatları,sayı isimlerine -ar,-er, şar, -şergetirelerek yapılır.

Herkes ikişer elma yedi. Çocuklar birer şeker aldı.

4- Kesir sayı sıfatları: Varlıkların bölünme miktarlarını bildirir.

$\mathrm{Bu}$ yıl yüde yüz başarı bildirir.

Yüzde on ihtimal sizinle gelebilirim.

5- Topluluk sayı sıfatları: Varlıkların topluluğunu bildirir. 
* Belirsizlik sıfatları:Belirsizlik sıfatları varlığın ne olduğunu ,sayısını, yerini miktarını açıcça belirtmez ${ }^{(11)}$ .En çok kullanılan belirsiz sıfatları şunlardır: Hiç, birçok, biraz, az, çok, kimi, bir, bütün .

* Soru sifatları :Varlıkların sorarak kullanılan sıfatlardır ${ }^{(12)}$. En çok kullanılan şunlardır:kaç, hangi, kaçıncı, nasıl kaçar ne.

\section{SONUÇ}

Türkçede sıfatlar vasıf ve belirtme isimleridir. Sıfatlar nesneleri vasıflandırma ve belirtme suretiyle karşılayan kelimedir. Sıfatlar asıl isimleri başka olan nesnelerin bir vasfını belirttikleri zaman sıfat, tek vasıftan ibrat olan nesneleri karşıladıkları zaman isim derler.

Türkçede sıfatlar vasıflandırdıklarını isimlerin önüne gelir. Türkçede sıfatlar, iyelik eki,isim hal ekleri ve çoğul eki de almaz. 


\section{P NOTLAR}

(1) Muharram Ergin.Türk Dil Bilgisi, stanbul basım evi s.218-219.

(2) sa Özkan.Gazi Üni,Türkçe Öğretim, Araştırma ve Uygulama Merkezi Tömer,Yayın No,4,s.107 sa Özkan.Gazi Üni, Türkçe Öğretim, Araştırma ve Uygulama Merkezi Tömer,Yayın No,4,s.108.

(4) (1).Muharram Ergin.Türk Dil Bilgisi, stanbul basım evi s.221.

(5) Tahir Necat, Dil Bilgisi, stanbul,s.140.

(6) sa Özkan.a.g.e.s.110.

(7) Fazıl Mehdi Beyat, Türkçe Dil Bilgisi, Bağdat Üniversitesi, Edebiyat Fakültesi,s.38-39.

(8) Sermet Sami Uysal, Yabancılara Türkçe Dersleri, Birinci Bölüm, s.147.

(9) Hamze Zülfikar, Doğru yazalım. Doğru konuşalım, Türk Dili Dergisi, s.243.

(10) Hamze Zülfikar, yabancılar için Türkçe dersleri,Ankara Üniversitesi Türkçe kursu yayınları:111, s.65,71.

(11) Çoban Hıdır Haydar ve Hidayet Kemal Bayatlı.Türk dil bilgisi, s.42.

(12) Şamil Fahri El-Allaf,çağdaş Türk Dil Bilgisi, Musul Üniversitesi Yayınları,s.99. 
حسن محد فرحان [439]

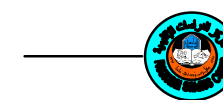

الصفات في اللغه التركيه

حسن محمد فرحان

مدرس مساعد/ قسم الدراسات اللغوية/مركز الدراسات الإقليمية/جامعة الموصل

\section{مستخلص البحث}

تاتي الصفات وي اللغه التركيه فبل الموصوف. وتعرف الصفه ناتها الكلمه التـي

توضح معاني الاسماء وتبين لنا خصائص واحوال الموجودات عافله ام غير عافله. كما تبين لنا (يضا عددها، الواتها، ترتيبها وفربها. تختلف الصفه عن الاســم مـن حيث عدم اخدها لواحق حالات الاسم والجمع والتملك. تتقسم الصفات من حيث الوظيقه الحى فسمين. الصفات الوصفيه والتعينيه. الصفات الوصفيه: هي الصفات التي تبين اوصاف الاثياء . الصفات التعينيه: هي التي تبين الاسم مــن حيـث الإثــارة، الاســتقهام، الابهـــام والسؤال. 


\section{KAYNAKLAR}

(1) Muharram Ergin.Türk Dil Bilgisi, stanbul ,1958.

(2) sa Özkan.Gazi Üni,Türkçe Öğretim,Araştırma ve Uygulama Merkezi Tömer,Yayın No,4,s.107 sa Özkan.Gazi Üni,Türkçe Öğretim,Araştırma ve Uygulama Merkezi Tömer, Ankara,2002

(4) (1) Muharram Ergin.Türk Dil Bilgisi, stanbul, 1958.

(5) Tahir Necat, Dil Bilgisi, stanbul,1971.

(6) sa Özkan.a.g.e.Ankara,2002

(7) Fazıl Mehdi Beyat, Türkçe Dil Bilgisi, Bağdat Üniversitesi, Edebiyat Fakültesi, Bağdat,1981.

(8) Sermet Sami Uysal, Yabancılara Türkçe Dersleri, stanbul ,s.148

(9) Hamze Zülfikar, Doğru yazalım .Doğru konuşalım, Türk Dili Dergisi

(10) Hamze Zülfikar, yabancılar için Türkçe dersleri,Ankara Üniversitesi Türkçe kursu yayınları: 111, Ankara, 1976.

(11) Çoban Hıdır Haydar ve Hidayet Kemal Bayatlı.Türk dil bilgisi, Bağdat, 1986.

(12) Şamil Fahri El-Allaf,çağdaş Türk Dil Bilgisi,Musul Üniversitesi Yayınları,Musul, 1991. 